\title{
Studies of Retinopathy and the Plasma Co-Factor of Platelet Hyperaggregation in Type 1 (Insulin-Dependent) Diabetic Children
}

\author{
R. D. Levin ${ }^{1}$, H.C. Kwaan ${ }^{2}$,J.G. Dobbie ${ }^{3}$, C. L.Fetkenhour ${ }^{3}$, H. S. Traisman ${ }^{4}$ and C. Kramer ${ }^{4}$ \\ ${ }^{1}$ Department of Medicine, Mount Sinai Hospital Medical Center, Rush Medical College, \\ ${ }^{2}$ Department of Medicine, VA Lakeside Hospital, Northwestern University, ${ }^{3}$ Department of Ophthalmology, Northwestern University, \\ and ${ }^{4}$ Department of Pediatrics, Children's Hospital, Northwestern University, Chicago, Illinois, USA
}

\begin{abstract}
Summary. Only one out of 73 children with young-onset Type 1 (insulin-dependent) diabetes for less than 10 years had retinopathy detectable with fluorescein retinal angiography. Although these fluorescent studies were normal, retinal abnormalities were detected in 19 out of 53 patients by electro-retinography and in four out of 28 patients by the 100 -hue colour test. We were unable to confirm recent reports indicating that most Type 1 diabetic patients have retinopathy detectable by fluorescein angiography. The diabetic plasma co-factor induces normal platelets to hyperaggregate in vitro. Plasma co-factor activities in adult diabetic patients have previously been shown to correlate with the degree of hyperaggregation, although in general, only those patients with severe retinopathy or nephropathy have high plasma activities. The plasma activities of 192 Type 1 diabetic patients were significantly higher than those of normal subjects $(p<$ 0.01 ). Of ten children with markedly elevated activities, nine did not have retinopathy.
\end{abstract}

Key words: Type 1 diabetes, platelets, plasma co-factor, fluorescein retinal angiography.

Type 1 (insulin-dependent) diabetic patients, particularly those with the onset of their disease before the age of 16 years, rarely have ophthalmoscopic evidence of retinopathy at the time of diagnosis, although $8 \%-40 \%$ will have some retinopathy after 10 years of disease. The progression of retinopathy is not relentless, and improvement in the retinal appearance occurs in 33\%-40\% of patients over a 10 -year period [1-3]. Retinal abnormalities may be detected even when the ophthalmoscopic appearance is normal. Recently, investigators who utilized fluorescent retinal angiography have reported that half of young- onset Type 1 diabetic patients possessed retinal microaneurysms within 5 years of diagnosis and that fluorescein angiography was useful for the early diagnosis of retinopathy [4-7]. This was not consistent with our experience, and therefore we were stimulated to examine our patients with fluorescein angiography. In addition, we used electro-retinography and the 100-hue colour vision test, as both tests have been reported to detect early retinopathy $[8,9]$.

Approximately $20 \%$ of patients who are diabetic for prolonged periods do not develop retinopathy. The development of retinopathy has been related to the presence of certain histocompatibility antigens [10], altered fibrinolysis [11], cigarette smoking [12], concomitant hypertension [13], and perhaps the most important of all, the quality and duration of diabetic control $[14,15]$. Whether hypercoagulability has a direct role in the progression of retinopathy has been the subject of persistent interest [16-18]. The hypercoagulable state in diabetes includes accelerated consumption of fibrinogen and platelets [19], increased platelet adhesiveness [20], and increased platelet aggregation in vitro [21] and in vivo [22].

There are at least two types of platelet abnormalities described, one involving elevated levels of von Willebrand factor which is thought to increase platelet adhesion, and the second, the enhanced aggregation of platelets, which correlates in degree with the plasma activity of a co-factor in some diabetic patients [23], and which is capable of enhancing the aggregation of platelets of normal subjects after ADP or collagen stimulation in vitro $[24,25]$. The co-factor effect is less with prostaglandin inhibition [26] and it seems probable that the relative production of capillary endothelial prostacyclin and platelet thromboxane are central to the whole question of platelet abnormalities in diabetes. It has been shown that elevated co-factor activity levels are more commonly pres- 

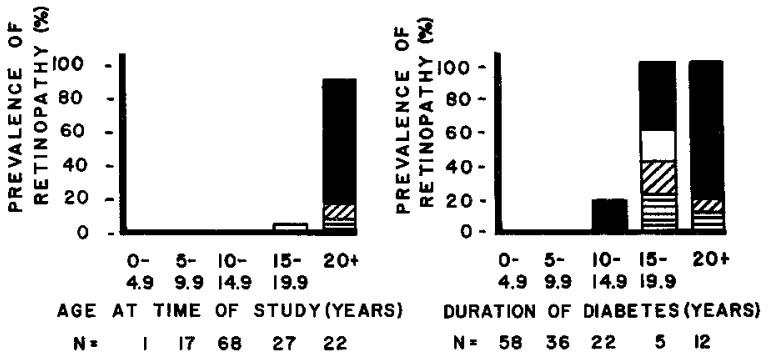

Fig. 1. The prevalence and severity of diabetic retinopathy as detected by ophthalmoscopy in 133 patients, as related to their age when studied and their duration of disease: grade $1=\mathbf{\square}$, grade 2 $=\square$, grade $3=\square$, and grade $4=$ 目

ent in patients with retinopathy or nephropathy [24, 25]. No correlation was found, however, between cofactor levels and those of blood glucose, non-esterified fatty acids, or of cholesterol, and the plasma cofactor activity was not affected by aspirin or sulphonylurea therapy [26]. No similar studies have been reported in children with Type 1 diabetes.

\section{Subjects and Methods}

\section{Subjects}

Two hundred and five classical Type 1 diabetic patients (102 males and 103 females) whose age of onset was before 16 years were studied during the years 1972-1977. Detailed ophthalmological information was available in the $133(65 \%)$ who attended our outpatient clinics regularly. In addition, $72(35 \%)$ were ascertained from a summer camp, but no ophthalmic assessments were available in these subjects. The mean age $( \pm S D)$ was $13.6 \pm 6.0$ years (range $4.5-37$ years) and the mean ( \pm SD) duration of diabetes was $6.7 \pm$ 6.2 years (range $0.1-32$ years). Forty-three normal children (22 males and 21 females) and 33 normal adults comprised a control group, mean age $( \pm S D) 19.2 \pm 12.7$ years.

\section{Ophthalmological Studies}

Our routine ophthalmological examinations comprised funduscopy, slit lamp examination and retinal photography. No patients had cataracts or refractive errors sufficient to influence the results, and all angiograms used were of high quality and evaluated by authors JGD and CLF. Fluorescein retinal angiography was performed with a $5 \mathrm{ml}$ bolus injection of $10 \%$ sodium fluorescein (Smith, Miller \& Patch, San German, Puerto Rico) into an antecubital vein; rapid sequence retinal photographs were taken under filters (Spectrotech, Lincoln, Massachusetts) appropriate for dye excitation and background barriers. Global scotopic electro-retinography was performed by the technique of Gouras [27] as adapted by Simonsen [28]. Colour vision defects were detected and quantitated with the Farnsworth-Munsell 100-hue test [9], which discriminates types of colour defects by reporting the number of errors made in arranging colour sequences.

Retinopathy was classified [24] as: grade 0 , normal; grade 1, occasional microaneurysms and early changes; grade 2 , numerous microaneurysms with venous beading and exudates present; grade 3 , severe microangiopathy with intraretinal and pre-retinal haemorrhages, and grade 4 , worse changes including more than two patches of neovascularization.

\section{Platelet Studies}

Technical details of the use of platelet aggregometry in vitro in the detection of the plasma co-factor have been published previously $[24,29]$. The co-factor potentiates the degree of second phase aggregation observed after small stimuli with ADP, as quantified by the light transmittance ratio. This is the ratio of the maximal second phase aggregation occurring in an 8:1:1 mixture of normal platelet-rich plasma, patient platelet-poor plasma, and the ADP stimulating solution, divided by the maximal aggregation occurring in an $8: 1: 1$ mixture of normal platelet-rich plasma, normal platelet-poor plasma, and the same ADP solution. We use an ADP concentration which causes $20 \%$ of maximal second-phase aggregation in the control, so that a light transmittance ratio over 1.0 indicates potentiation of second phase aggregation and a ratio under 1.0 indicates inhibition, the maximal ratio being 5.0. Light transmittance ratios are reproducible from day to day, but elevations of several months' duration occur during active retinopathy.

Blood was drawn before eye studies were done, and was anticoagulated $1: 9$ with $0.147 \mathrm{~mol} / 1$ trisodium citrate. The plasma was immediately separated and stored at $-20^{\circ} \mathrm{C}$ until analysis.

Statistical analysis was carried out using the two-tailed Student's t-test except where otherwise indicated.

This study was approved by the Human Investigations Committee of Northwestern University and carried out according to the Declaration of Helsinki.

\section{Results}

\section{Fundoscopy}

The prevalence of retinal pathology, determined by ophthalmoscopy, is shown in Figure 1. Of the 133 diabetic patients in whom data were available, none of the 84 patients under 15 years of age had evidence of retinopathy, while 22 out of 24 patients older than 20 years of age had retinopathy. Ophthalmoscopy detected retinopathy in none of the 94 patients who were diabetic for less than 10 years, and in only five out of 22 who were diabetic $10-14.9$ years. Of the 17 patients who were diabetic for longer periods, all had some degree of retinopathy.

\section{Fluorescein Angiography}

No retinopathy was observed with fluorescein angiography in the 67 patients younger than 15 years of age, but all patients older than 20 years had evidence of retinopathy. No retinopathy was observed in the 74 patients who were diabetic for less than 10 years, while all who were diabetic for 15 or more years had some retinopathy. Only one patient was identified with no retinopathy by ophthalmoscopy who had microaneurysms detected by fluorescein angiography. 


\section{Electro-retinography}

The electro-retinogram b-wave potential was determined during dark-adapted corneal electro-retinography in 55 patients, all of whom also had fluorescein angiography. The normal amplitude is over $175 \mu \mathrm{v}$. Twenty out of 55 patients had less than normal values, of whom only two had known retinopathy. One was a 20 year old female with diabetes for 12 years with grade 2 retinopathy, neuropathy, amenorrhoea, and an oscillatory potential of $98 \mu \mathrm{v}$, while the other was a 15 year old female who had been diabetic for $81 / 2$ years and who had sparse grade 1 retinopathy and an oscillatory portential of $192 \mu \mathrm{v}$. There was no linear relationship of $b$-wave oscillatory potential with either the duration of diabetes or with the age of these patients.

\section{Colour Vision}

Twenty-nine patients who had undergone fluorescein angiography were assessed with the 100-hue colour vision test. Only four individuals had abnormal responses and none of these had retinopathy. Of the 25 patients with a normal response to the 100 -hue test, we found normal fundi in 24 patients and grade 1 retinopathy in one patient.

\section{Platelet Studies}

Figure 2 indicates the light transmission ratio of 192 patients in relation to their age. The control population's values were significantly lower than those of the diabetic patients (analysis of covariance $\mathrm{F}$ ratio $=$ $14.6, p<0.01$ ). Figure 3 indicates the light transmission ratio values of the 192 patients in relation to their known duration of diabetes. Ten children had values higher than three SD above the mean of the group, and thus are likely to represent an unique subset amidst the general group. Retinal studies were normal in nine of these ten patients, while one, a 27 year-old male with diabetes for 15 years, had grade 1 retinopathy. The analysis of covariance is used here as the group required two parameters to define normal variation; the lower limit of the illustrated slopes was positive in both Figures $(p<0.05)$.

\section{Discussion}

These data support other findings $[2,3]$ that retinopathy is uncommon within the first years after the diagnosis of young-onset Type 1 diabetes, and provides no evidence that retinopathy exists at a subclinical level detectable by fluorescein retinal angiography.

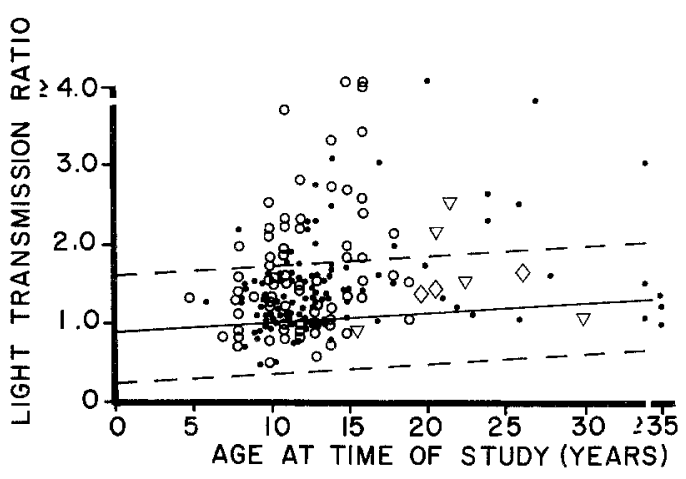

Fig. 2. The relationship of the plasma co-factor activities of $192 \mathrm{di}-$ abetic patients with their age when studied. Severity of retinopathy according to fluorescein retinal angiography: $=$ no data available, $O=\operatorname{grade} 0, \nabla=\operatorname{grade} 1, \diamond=\operatorname{grade} 2$. Mean $(--) \pm 2 \mathrm{SD}$ ( - - ) of the values in normal subjects

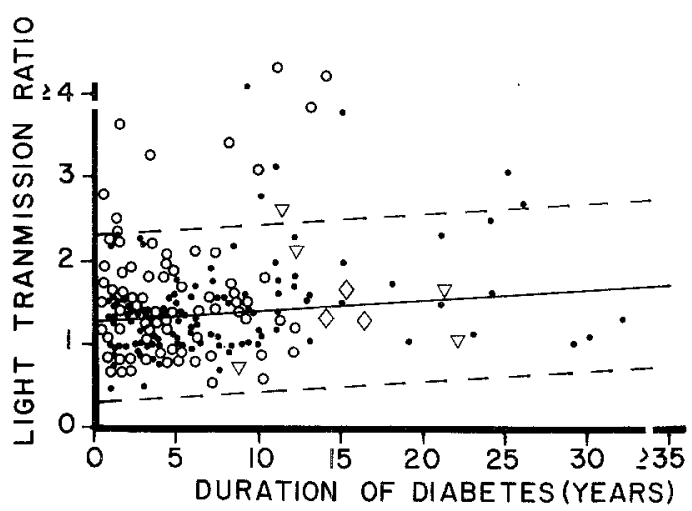

Fig. 3. The relationship of the plasma co-factor activities of $192 \mathrm{di}-$ abetic patients with their duration of disease, with symbols as in Fig. 2. Mean (--) \pm 2 SD (- - - ) of the values of the diabetic patients, excluding the 10 subjects whose values exceeded the mean $\pm 3 \mathrm{SD}$

Examinations by ophthalmoscopy, slit lamp, and retinal photography found only 21 out of 133 patients to have retinopathy. With fluorescein angiography, only eight out of 94 children were found to have retinopathy. We could not detect retinopathy in any patient with diabetes for less than 5 years, and found early changes in only one patient with diabetes for less than 10 years. Our population must therefore differ vastly from that of Malone et al. [7] who described fluoroangiographic evidence of retinopathy in $75 \%$ of their young-onset Type 1 diabetic patients who had had their disease for up to 10 years, and more remarkably, found retinopathy in 20 out of 39 children who were diabetic for less than one year. It must also differ from that of Brooser et al. [6] where fluoroangiography found retinopathy in half their patients who were known to have diabetes for up to 5 years, and whose ophthalmoscopic appearance was normal. The study of Toussaint and Dorchy [30] reported fluoroangio- 
graphic evidence of microaneurysms in one out of nine patients with diabetes of less than 5 years' duration, and in eight out of 23 of under 10 years' duration, with vascular abnormalities in $75 \%$ of their patients who were diabetic for over 6 years. Although we cannot explain the discrepancies, we feel that subtle patient selection factors are involved and, in particular, patient referral patterns.

Fluoroangiographic studies did not contribute to the early diagnosis of diabetic retinopathy, for out of 87 patients with a normal ophthalmoscopic appearance, only one had background changes. The electroretinographic studies revealed reduced oscillatory potentials in 20 out of 55 patients tested, although only two had retinopathy detected by fluoroangiography. This is similar to the data of Yonemura et al. [8] who reported decreased potentials in seven out of 13 adult patients whose funduscopic appearances were normal. In our patients, there was no trend of deterioration with increasing duration of diabetes. The colour vision tests detected normal vision in one patient with known retinopathy and abnormal colourvision in four out of 28 patients without retinopathy; minimal colour vision defects have similarly been reported in adult diabetic patients $[9,31]$.

We found little value for these three tests in the early, specific diagnosis of retinopathy, but we recognize that each method does not necessarily measure the same physiological abnormality. Cunha-Vas et al. $[15,32]$ have utilized vitreous fluorophotometry to demonstrate the breakdown of the blood-retinal barrier in diabetic patients whose fluoroangiographic findings were normal. They have shown that progressive deterioration was particularly noted in patients with poor metabolic control. The increased retention of fluorescein by the vitreous has also been reported in $80 \%$ of young-onset Type 1 diabetic patients [33], but as patients with background retinopathy did not have significantly more retention than those without retinopathy, interpretation is difficult.

This study presents data of the plasma co-factor causing platelet hyperaggregation in young-onset Type 1 diabetic patients. Plasma co-factor activities may be markedly elevated in diabetic adults with advanced microangiopathy [25]. Our young patients had higher mean light transmittance ratios than the normal subjects, even though few patients with advanced disease were included in our study population. Ten of these patients, nine of whom had no detectable retinopathy, had markedly elevated light transmittance ratios. This elevation of co-factor activity has similarly been reported in studies of latent diabetic patients and in patients without evidence of vascular disease [26]. Two laboratories have been unable to demonstrate co-factor activity $[34,35]$, both of which found platelet hyperaggregation, although neither could ascertain if, in addition, plasma factors were present which potentiated aggregation. As the co-factor is not universally present, patient selection may have also influenced their results.

We conclude that diabetic patients have higher plasma co-factor activities than normal subjects and that a few patients (only ten out of 192 patients in this study) may have markedly elevated levels. Cohort studies are required to determine if a newly-diagnosed diabetic patient will acquire additional platelet hyperaggregation or microangiopathy mediated by the plasma co-factor. Particular attention will be focused upon the rate of progression of the ten patients in this study with plasma co-factor activities higher than those usually encountered in diabetic patients, for their course may assist in understanding the role of hypercoagulability in the progression of diabetic retinopathy.

Acknowledgments. The technical assistance of A.Berzins and E. Choromokos is gratefully acknowledged. This work was supported by a grant from the Bertha and Henry Brownstein Foundation, Chicago, Illinois, USA.

\section{References}

1. Kornerup T (1955) Studies in diabetic retinopathy: an investigation of 1000 cases. Acta Med Scand 153: 81-101

2. White $P(1960)$ Childhood diabetes. Its course, and influence on the second and third generations. Diabetes $9: 345-355$

3. Larsson Y, Sterky G (1962) Long-term prognosis in juvenile diabetes mellitus. Acta Paediat (Uppsala) 51 (Suppl CXXX): $5-76$

4. Barta L, Brooser G, Molnar M (1971) Diagnostic value of retinal fluorescence in juvenile diabetes. Acta Paediatr Acad Sci Hung 12: 243-245

5. Barta L, Brooser G, Molnar M (1972) Diagnostic importance of fluorescein angiography in infantile diabetes. Acta Diabetol Lat 9: 290-298

6. Brooser G, Barta L. Anda L, Molnar M (1975) Frühdiagnose der Mikroangiopathie bei kindlichem Diabetes. Klin Monatsbl Augenheilk 166:233-236

7. Malone JI, Van Cader TC, Edwards WC (1977) Diabetic vascular changes in children. Diabetes 26: 673-679

8. Yonemura D, Aoki T, Tsuzuki K (1962) Electroretinogram in diabetic retinopathy. Arch Ophthalmol 68:19-24

9. Linksz A (1968) The Munsell color circle and the FarnsworthMunsell 100-hue test. In: Whitcomb MA, Benson W (ed) The measurement of visual function. Armed Forces, NRC Committee on Vision, National Academy of Sciences, National Research Council, Washington, DC, pp 82-90

10. Barbosa J, Ramsay RC, Knobloch WH, Cantril HL, Noreen H, King R, Yunis E (1980) Histocompatibility antigen frequencies in diabetic retinopathy. Am J Ophthalmol 90: 148-153

11. Almer L-O, Pandolfi M, Nilsson IM (1975) Diabetic retinopathy and the fibrinolytic system. Diabetes 24: 529-534

12. Paetkau ME, Boyd TAS, Winship B, Grace M (1977) Cigarette smoking and diabetic retinopathy. Diabetes $26: 46-49$

13. Knowler WC, Bennett PH, Ballintine EJ (1980) Increased incidence of retinopathy in diabetics with elevated blood pressure. 
A six-year follow-up study in Pima Indians. N Eng J Med 302: 645-650

14. Peterson CM, Jones RL, Koenig RJ, Melvin ET, Lehrman ML (1977) Reversible hematologic sequelae of diabetes mellitus. Ann Intern Med 86: 425-429

15. Cunha-Vas JG, Fonseca JR, Abreu JF, Ruas MA (1978) A follow-up study by vitreous fluorophotometry of early retinal involvement in diabetes. Amer J Ophthalmol 86: 467-473

16. Waitzman MB, Colley AM, Nardelli-Olkowska K (1977) Metabolic approaches to studies on diabetic microangiopathy. Diabetes 25: $510-519$

17. Bern MM (1978) Platelet functions in diabetes mellitus. Diabetes $27: 342-350$

18. Colwell JA, Halushka PV, Sarji KE, Lopes-Virella MF, Sagel J (1979) Vascular disease in diabetes. Pathophysiological mechanisms and therapy. Arch Intern Med 139:225-230

19. Ferguson JC, Mackay N, Philip JAD, Sumner DJ (1973) Platelet and fibrinogen studies in diabetes mellitus. $\mathrm{Br} \mathbf{J}$ Haematol 25:545

20. Hellem AJ (1971) ADP induced platelet adhesiveness in diabetes mellitus with complications. Acta Med Scand 190: 291-295

21. Heath H, Brigden WD, Canever JV, Pollock J, Hunter PR, Kelsey J, Bloom A (1971) Platelet adhesiveness and aggregation in relation to diabetic retinopathy. Diabetologia $7: 308-315$

22. Fleischman AI, Bierenbaum ML, Stier A, Somol H, Watson PB (1975) In vivo platelet function in diabetes mellitus. Thromb Res 9:467-471

23. Colwell JA, Halushka PV, Sarji K, Levine J, Sagel J, Nair RMG (1976) Altered platelet function in diabetes mellitus. Diabetes 25 (Suppl 2): 826-831

24. Kwaan HC, Colwell JA, Cruz S, Suwanwela N, Dobbie JG (1972) Increased platelet aggregation in diabetes mellitus. J Lab Clin Med 80: 236-246

25. Colwell JA, Sagel J, Crook L, Chambers A, Laimins M (1977) Correlation of platelet aggregation, plasma factor activity, and megathrombocytes in diabetic subjects with and without vascular disease. Metabolism 26: 279-285

26. Colwell JA, Chambers A, Laimins M (1975) Inhibition of labile aggregation-stimulating substance (LASS) and platelet aggregation in diabetes mellitus. Diabetes 24: 684-687
27. Gouras P (1970) Electroretinography. Some basic principles. Invest Ophthalmol 9:557-569

28. Simonsen SE (1969) ERG in juvenile diabetics: A prognostic study. In: Goldberg MF, Fine SL (eds) Symposium on the treatment of diabetic retinopathy. US Public Health Service Pub 1890. US Government Printing Office, Washington, DC, pp 681-689

29. Levin RD, Kwaan HC, Dobbie JG, Fetkenhour CL, Traisman HS (1981) Partial purification and studies of the plasma co-factor which potentiates platelet aggregation in diabetes mellitus. $\mathrm{J}$ Lab Clin Med 98: 519-527

30. Toussaint D, Dorchy H (1974) Exploration angiofluorescinique de la retinopathie diabetique infantile: etude preliminaire. Bull Soc Belge d'Ophthalmol 168: 783-800

31. Kinnear PR, Aspinall PA, Lakowski R (1972) The diabetic eye and colour vision. Trans Ophthalmol Soc UK 92: 69-78

32. Cunha-Vas JG, Abreu JRF, Campos AJ, Figo G (1975) Early breakdown of the blood-retinal barrier in diabetes. $\mathrm{Br} \mathbf{J}$ Ophthalmol 59:649-656

33. Krupin T, Waltman SR, Oestrich C, Santiago J, Ratzan S, Kilo C, Becker B (1978) Vitreous fluorophotometry in juvenile-onset diabetes mellitus. Arch Ophthalmol 96:812-814

34. Bensoussan D, Levy-Toledano S, Passa P, Caen J, Canivet J (1975) Platelet hyperaggregation and increased plasma level of von Willebrand factor in diabetics with retinopathy. Diabetologia 11:307-312

35. Coller BS, Frank RN, Milton RC, Gralnick HR (1978) Plasma cofactors of platelet function: correlation with diabetic retinopathy and hemoglobins $A_{1 a-c}$. Studies in diabetic patients and normal persons. Ann Intern Med 88:311-316

Received: 20 May 1981

and in revised form: 3 February 1982

Robert Levin M.D.

Division of Hematology

Mount Sinai Hospital Medical Center

Chicago, Illinois 60608, USA 